\title{
Effect of Cytochalasin B Treatment on the Improvement of Survival Rate in Vitrified Pig Oocyte
}

\author{
In-Sul Hwang1, Mi-Ryung Park¹, Tae-Uk Kwak¹, Sang-Hyun Park¹, Ji-Hyun Lim¹, \\ Sung Woo Kim², and ‘Seongsoo Hwang ${ }^{1}$ \\ ${ }^{I}$ Animal Biotechnology Division, National Institute of Animal Science, Wanju 55365, Korea \\ ${ }^{2}$ Animal Genetics Resources Research Center, National Institute of Animal Science, Namwon 55717, Korea
}

\begin{abstract}
To improve survival rates of vitrified pig oocytes, the treatment of cytoskeletal stabilizer on an appropriate time is one of the possible approaches. However, the exact treatment timing and effect of cytoskeletal stabilizer such as cytochalasin $\mathrm{B}(\mathrm{CB})$ is not well known during oocyte vitrification procedures. Thus, the present study was conducted to determine optimal treatment timing of $\mathrm{CB}$ during vitrification and warming procedures. In experiment 1 , the survival rates of the postwarming pig oocytes were analyzed by fluorescein diacetate (FDA) assays with 4 classifications. In results, post-warming oocytes showed significantly ( $p<0.05$ ) decreased number of alive oocytes $(31.8 \%$ vs. $86.4 \%)$ compared to fresh control. In detail, the significant difference $(p<0.05)$ was found only in strong fluorescence $(18.2 \%$ vs. $70.5 \%)$ not in intermediate fluorescence groups (13.6\% vs. 15.9\%). In experiment 2, CB was treated before (CB-Vitri) and after (Vitri-CB) vitrification. In results, group of Vitri-CB showed significantly $(p<0.05)$ higher $(91.6 \%)$ survival rates compared to group of CB-Vitri $(83.7 \%)$, significantly $(p<0.05)$ and comparable with group of Vitri Control $(88.7 \%)$ by morphological inspection. In FDA assay results, group of Vitri-CB showed significantly $(p<0.05)$ higher $(44.2 \%)$ survival rates compared to groups of CB-Vitri $(36.7 \%)$ and Vitri Control $(35.1 \%)$. In conclusion, the increased survival rates of post-warming pig oocyte treated with Vitri-CB method are firstly described here. The main finding of present study is that the $\mathrm{CB}$ treatment during recovery could be helpful to refresh the post-warming pig oocyte resulting its improved survival rates.
\end{abstract}

Key words : Pig oocyte, Vitrification, Cytochalasin B, Cryoinjury, Viability

\section{INTRODUCTION}

Cryopreservation of reproductive cells and tissues is one of the most important parts of biomedical and agricultural researches, which can be used to overcome an infertility of human beings and to preserve valuable genetic resources of endangered and transgenic animals. One of the powerful methods to cryopreserve reproductive cells with decreased cryoinjuries is ultra-rapid freezing method such as vitrifi- cation. Recently, a vitrification method has been applied widely to cryopreserve the cells in the mammalian species, including pig (Isachenko et al., 1998), cattle (Fuku et al., 1995), mice (Kono et al., 1991), and human (Boyer et al., 2012). Especially in pig oocyte, it is well known that the oocytes matured in vitro are very difficult to cryopreserve because of its higher sensitivity to cryoinjuries compared to other mammalian oocytes like human (Fabbri et al., 1998), cattle (Hwang et al., 2013), and small rodent (dela

\footnotetext{
Manuscript received July 19, 2018, Received in revised form August 16, 2018, Accepted August September 3, 2018

${ }^{\dagger}$ Corresponding Author : Seongsoo Hwang, Ph.D., Animal Biotechnology Division, National Institute of Animal Science, Wanju 55365, Korea. Tel: +8263-238-7253, Fax: +82-63-238-7297, E-mail: hwangss@korea.kr

This is an Open Access article distributed under the terms of the Creative Commons Attribution Non-Commercial License (http:// creative-commons.org/licenses/by-nc/3.0) which permits unrestricted non-commercial use, distribution, and reproduction in any medium, provided the original work is properly cited.
} 
Pena et al., 2001).

According to our previous report, lipid content, quality, size, and shape of oocytes were responsible for cryotolerance (Hwang \& Hochi, 2014). In pig, limited studies have been demonstrated a successful vitrification using immature and in vitro matured oocytes (Rojas et al., 2004; Albarracin et al., 2005). Vitrification of in vitro-matured oocytes might be occur various kinds of cryoinjuries caused by high concentration of cryoprotectant (CPA) in the vitrification medium (Hwang \& Hochi, 2014). Exposure of oocyte to CPA has been shown to induce cryoinjuries such as microtubule depolymerization and premature exocytosis of cortical granules resulting decreased survival rates and developmental failure (Coticchio et al., 2009; Lowther et al., 2009). The CPA exposed oocytes during vitrification had been changed not only distribution and function of mitochondria but also mitochondrial ultrastructure (Vallorani et al., 2012; Dai et al., 2015). An abnormal distribution and dysfunction of mitochondria in oocytes were closely involved in the activation of apoptotic mechanisms resulting oocyte dead (Vallorani et al., 2012). Therefore, vitrification method for pig oocyte is still required to be improved much in survival, fertilization, and developmental rates (Mullen \& Fahy, 2012; Somfai et al., 2012).

To improve survival rates of vitrified oocytes, it is essentially needed a modification of vitrification procedures, development of vitrification devices, and treatment of chemicals during a vitrification procedure. Many chemicals were applied during recovery culture such as signal pathway inhibitors, antioxidants, and cytoskeletal stabilizers (Hwang et al., 2013; Hwang et al., 2016; Pitchayapipatkul et al., 2017). One of the common cytoskeletal stabilizers is cytochalasin B (CB) widely applied for softening of oocyte before conducting micromanipulation such as somatic cell nuclear transfer because of its safety on oocytes (Hwang et al., 2015). Chemical treatments during post-warming culture after vitrification can be one of the possible approaches to help oocyte to regain its ability to develop. Therefore, the present study was conducted to determine optimal treatment timing of $\mathrm{CB}$ during vitrification and warming procedures.

\section{MATERIALS \& METHODS}

\section{Experimental design}

In experiment 1 , the survival rates of the post-warming pig oocytes were analyzed by fluorescein diacetate (FDA) assays with 4 classifications as shown in Fig. 1. After vitrification/warming and recovery culture, the pig oocytes were stained with FDA and analyzed its survival rates. The oocytes with strong and intermediate green fluorescence were determined as alive, but weak and none signals were classified as dead. In experiment 2, CB was treated before (CB-Vitri) and after (Vitri-CB) vitrification. Then, the survival rates of post-warming oocytes were analyzed by morphology and FDA assay to determine an appropriate timing and effect of CB treatment.

\section{In vitro maturation oocytes}

All chemicals were purchased from Sigma-Aldrich Chemicals (St. Louis, MO, USA) unless stated otherwise. Prepu-

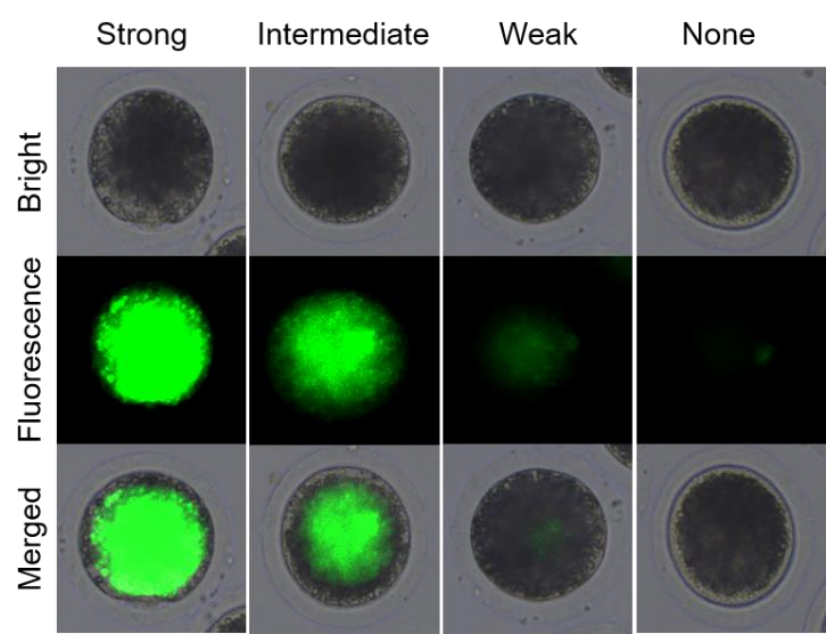

Fig. 1. Categorization of viable post-warming pig oocytes by FDA assay. Oocytes with strong and intermediate signal were determined as alive oocyte while weak and none signal were determined as dead oocyte. FDA, fluorescein diacetate. 
bertal pig ovaries were obtained from local slaughterhouse Nonghyup Moguchon, Gimje, Korea) and transported to the laboratory within thermos containing $30^{\circ} \mathrm{C}$ to $35^{\circ} \mathrm{C}$ of saline. Then, 3-6 $\mathrm{mm}$ follicles were aspirated by disposable syringe with an 18 gauge needle and cumulus oocytes complexes (COCs) with several compact layer of cumulus cells were selected for in vitro maturation. The COCs were cultured in the hepes-buffered Tissue Culture Medium (TCM)-199 (Gibco BRL, NY, USA) supplemented with $10 \%$ porcine follicular fluid $(\mathrm{pFF}), 3.05 \mathrm{mM}$ D-glucose, $0.57 \mathrm{mM}$ cysteine, $0.91 \mathrm{mM}$ sodium pyruvate, $0.5 \mu \mathrm{g} / \mathrm{mL}$ FSH, $0.5 \mu \mathrm{g} / \mathrm{mL}$ LH, $10 \mathrm{ng} / \mathrm{mL}$ EGF, $75 \mu \mathrm{g} / \mathrm{mL}$ penicillin $\mathrm{G}$ and $50 \mu \mathrm{g} / \mathrm{mL}$ streptomycin in a four-well dish for $22 \mathrm{~h}$ at $38.5^{\circ} \mathrm{C}$ under $5 \% \mathrm{CO}_{2}$ in air. Then the oocytes were matured in vitro within the maturation medium described above without $\mathrm{FSH}$ and $\mathrm{LH}$ for additional $22 \mathrm{~h}$ at $38.5^{\circ} \mathrm{C}$ under $5 \% \mathrm{CO}_{2}$ in air. After in vitro maturation, the oocytes were examined comprehensively for the extrusion of the first polar body after removal of cumulus cells by treatment of $0.1 \%$ hyaluronidase solution with gentle pipetting.

\section{Vitrification and warming of oocytes}

The matured oocytes were conducted to a vitrification and warming according to the method described previously (Hwang et al., 2013). Briefly, the oocytes were equilibrated in the base medium [TCM-199 with $20 \%$ fetal bovine serum (FBS, Gibco BRL)], supplemented with 7.5\% ethylene glycol (EG), and 7.5\% dimethyl sulfoxide (DMSO) for $5 \mathrm{~min}$. Then, the equilibrated oocytes were transferred into the vitrification solution consisting of $20 \%$ FBS, $15 \%$ EG, $15 \% \mathrm{DMSO}$, and $0.5 \mathrm{M}$ sucrose for $1 \mathrm{~min}$ at room temperature. During that time, around 15 oocytes were mounted onto the tip of the Cryotop (Kitazato BioPharma, Shizuoka, Japan) with a minimal volume of the vitrification solution $(<0.1 \mu \mathrm{L})$ and then quickly plunged into liquid nitrogen $\left(\mathrm{LN}_{2}\right)$. After storage for more than 1 week in the $\mathrm{LN}_{2}$, the vitrified oocytes were warmed by soaking the tip of the Cryotop into the pre-warmed base medium con- taining $1 \mathrm{M}$ sucrose at $38.5^{\circ} \mathrm{C}$ for $1 \mathrm{~min}$. Then, the oocytes were transferred into the base medium containing 0.5 , 0.25 , and $0 \mathrm{M}$ sucrose (for 3, 5, and $5 \mathrm{~min}$, respectively) at room temperature $\left(25.0^{\circ} \mathrm{C}\right)$. The predicted freezing and warming rates of the Cryotop method informed by the manufacturer were $-23,000$ and $42,000^{\circ} \mathrm{C} / \mathrm{min}$, respectively.

\section{Recovery culture and treatment of cytochalasin B}

After vitrification and warming, the oocytes were washed 3 times and conducted to recovery culture with TCM-199 with $5 \% \mathrm{FBS}, 0.2 \mathrm{mM}$ sodium pyruvate, $75 \mu \mathrm{g} / \mathrm{mL}$ penicillin $\mathrm{G}$, and $50 \mu \mathrm{g} / \mathrm{mL}$ streptomycin in a 4 -well dish for $2 \mathrm{~h}$ at $38.5^{\circ} \mathrm{C}$ under $5 \% \mathrm{CO}_{2}$ in air (30 oocytes per well). The $\mathrm{CB}$ was treated before (CB-Vitri) vitrification procedure for 30 minutes and after (Vitri-CB) vitrification procedure from start of recovery culture for 30 minutes with concentration of $7.5 \mu \mathrm{g} / \mathrm{mL}$.

\section{Analysis of post-warming survival rates}

The survival of post-warming oocytes was evaluated based on our previous study (Hwang et al., 2013). Briefly, the survival was estimated by morphological changes on oolemma and zona pellucida firstly. Demarcation of membrane, zona pellucida fracture, and cytoplasmic distribution were comprehensively checked by microscope. Then, the survival rates based on esterase enzyme activity by FDA assay was assessed. After recovery culture with or without $\mathrm{CB}$, the oocytes were washed 3 times in PBS for 1 min, followed by incubation with $2.5 \mathrm{mg} / \mathrm{mL}$ of FDA for 1 $\min$. Then, the oocytes were washed 3 times again in PBS containing $0.1 \%$ BSA and observed under an epifluorescence microscope (Leica Microsystems, Wetzlar, Germany). As shown in Fig. 1, the alive oocytes showed strong and intermediate green fluorescence, whereas the dead oocytes showed a weak or none fluorescent signals.

\section{Statistical analysis}

All experiments were replicated at least 4 times in each 
Table 1. Survival rates of post-warming pig oocytes examined by FDA assay

\begin{tabular}{|c|c|c|c|c|c|c|c|}
\hline \multirow{3}{*}{ Groups } & \multirow{3}{*}{$\begin{array}{c}\text { No. of oo- } \\
\text { cytes exam- } \\
\text { ined }\end{array}$} & \multicolumn{6}{|c|}{ No. of oocytes determined as* } \\
\hline & & \multicolumn{3}{|c|}{ Alive (\%) } & \multicolumn{3}{|c|}{ Dead $(\%)$} \\
\hline & & Strong & Intermediate & Total & Weak & None & Total \\
\hline Fresh control & 44 & $31(70.5)^{\mathrm{a}}$ & $7(15.9)^{a}$ & $38(86.4)^{\mathrm{a}}$ & $6(13.6)^{\mathrm{a}}$ & $0(0.0)^{\mathrm{a}}$ & $6(13.6)^{\mathrm{a}}$ \\
\hline Post-warming & 44 & $8(18.2)^{b}$ & $6(13.6)^{\mathrm{a}}$ & $14(31.8)^{b}$ & $18(40.9)^{\mathrm{b}}$ & $12(27.3)^{b}$ & $30(68.2)^{b}$ \\
\hline
\end{tabular}

* Data are represented as total number (mean) of four replicates in each group.

${ }^{\mathrm{a}, \mathrm{b}}$ Different superscripts denote significance within columns $(p<0.05)$.

FDA, fluorescein diacetate.

group. All data were analyzed by Origin 8 software (OriginLab Corporation, Northampton, MA, USA) by applying one-way analysis of variance with arcsine transformation. A value of $p<0.05$ was considered to be significant.

\section{RESULTS}

\section{Survival rates of post-warming pig oocytes}

According to the results indicated in the Table 1, the post-warming oocytes showed significantly decreased the number of the alive compared to the fresh control $(31.8 \%$ vs. $86.4 \%)(p<0.05)$. In detail, the significant difference $(p<0.05)$ was found only in strong fluorescence $(18.2 \%$ vs. $70.5 \%)$, but not in intermediate fluorescence groups $(13.6 \%$ vs. $15.9 \%)$. On the other hand, the number of the dead oocytes were significantly increased $(68.2 \%$ vs. $13.6 \%)$ compared to fresh control $(p<0.05)$. The rates of the dead oocytes in both weak ( $40.9 \%$ vs. $13.6 \%)$ and none $(27.3 \%$ vs. $0.0 \%$ ) fluorescence groups were significantly different compared to the fresh control $(p<0.05)$, respectively.

\section{Effect of $\mathrm{CB}$ treatment timing on vitrified-warmed} pig oocytes

Pig oocytes were treated with $\mathrm{CB}$ before and after vitrification procedures to determine appropriate treatment timing for the improvement of survival rates in the postworming oocytes. After recovery culture, all the vitrified oocytes were subjected to test its viability by morphological inspection and FDA assay. As shown in Table 2, the Vitri-CB group showed significantly higher survival rates

Table 2. Effect of Cytochalasin B on viability of post-warming pig oocytes

\begin{tabular}{|c|c|c|c|}
\hline \multirow{2}{*}{ Groups } & \multirow{2}{*}{$\begin{array}{c}\text { No. of } \\
\text { oocytes examined }\end{array}$} & \multicolumn{2}{|c|}{ No. of survived oocytes analyzed by $(\%)^{*}$} \\
\hline & & Morphology & FDA assay \\
\hline Fresh control & 57 & $57(100 \pm 0.0)^{\mathrm{a}}$ & $48(84.2 \pm 1.6)^{\mathrm{a}}$ \\
\hline Vitri-control & 97 & $86(88.7 \pm 2.8)^{\mathrm{bc}}$ & $34(35.1 \pm 1.5)^{\mathrm{c}}$ \\
\hline CB-Vitri & 98 & $81(83.7 \pm 2.6)^{\mathrm{c}}$ & $36(36.7 \pm 1.6)^{\mathrm{c}}$ \\
\hline Vitri-CB & 95 & $95(91.6 \pm 2.6)^{\mathrm{b}}$ & $42(44.2 \pm 1.0)^{\mathrm{b}}$ \\
\hline
\end{tabular}

* Data are represented as total number (mean \pm SEM) of four replicates in each group.

${ }^{\text {a-c }}$ Different superscripts denote significance within columns $(p<0.05)$.

FDA, fluorescein diacetate; Vitri-Control, vitrification only; CB-Vitri, CB treatment before vitrification/warming; Vitri$\mathrm{CB}, \mathrm{CB}$ treatment after vitrification/warming. 
(91.6\% vs. $83.7 \%$ ) in morphological inspection compared to the CB-Vitri group $(p<0.05)$, respectively, but lower than that of the Fresh Control $(100.0 \%)(p<0.05)$. Interestingly, the CD-Vitri group showed comparably lower survival rate than that of Vitri-Control (88.7\%). According to the results of FDA assay, the Vitri-CB group showed significantly higher (44.2\%) survival rates compared to CBVitri (36.7\%) and Vitri-Control (35.1\%) groups $(p<0.05)$, respectively.

\section{DISCUSSION}

Morphological inspection of an oocyte quality and viability by assessment of morphological changes on oolemma and zona pellucida is widely used to select good quality oocytes and embryos (Van Soom et al., 2003; Hamamah, 2005). To determine the viability and quality of oocyte, demarcation of membrane, perivitelline space, zona pellucida fracture, and cytoplasmic distribution were firstly needed to be checked before conducting the next step of experiment associated with assisted reproductive technology (Wang \& Sun, 2006; Balaban et al., 2012). However, the result of morphological assessment does not reflect always to fertilization rates and oocyte/embryo quality after conducting assisted reproductive technology (De Sutter et al., 1996; Balaban et al., 1998; Hwang et al., 2016). Previous study showed that high survival rates by morphological inspection did not reflect high quality of oocyte/embryo and developmental competence (Hwang et al., 2016).

On the other hand, the FDA assay has been widely applied to determine the viability and quality of embryos (Mohr \& Trounson, 1980; Noto et al., 1991) and oocytes (Didion et al., 1990; Hwang et al., 2016). Because many lipid droplets were in cytoplasm of pig and cattle oocytes, the oocytes were not visible inside by microscope (Kikuchi et al., 2002). Therefore, the FDA assay to determine survival rates and to compare the difference with survival rates by morphological inspection of post-warming pig oocytes.

In the present study, the survival rate of the postworming oocytes was different between morphological inspection and FDA assay. Although high rate of the vitrified oocytes looked like survive $(83.7 \%$ to $91.6 \%)$ by morphological inspection, the survive rate of the oocytes was decreased (35.1\% to $44.2 \%$ ) by FDA assay. It can be postulated that the morphological inspection was not sufficient to assess viability, at least in the post-warming pig oocyte. To improve the accuracy of FDA assay result, it was subdivided into 4 classifications of strong, intermediate, weak, and none green fluorescence as shown in Fig. 1. As shown Table 1, the post-warming pig oocytes vitrified by conventional vitrification protocol showed significantly $(p<0.05)$ decreased numbers of alive oocytes compared to the Fresh Control group like our previous study (Hwang et al., 2016). It could be understood that the decreased survival rates were caused by subdivided categorization of alive and dead oocytes. And this result could be indicated that the post-warming oocytes were well divided into alive and dead because only the oocyte having higher enzymatic activity (activation of fluorescence) and cell-membrane integrity (retention of fluorescent) can be detected strong and intermediate green fluorescence. In the present study, the increased number of weak fluorescence in the postwarming oocytes could be indicated that the oocytes lost enzymatic activity and cell-membrane integrity during vitrification procedures.

To overcome cryoinjuries occurred by vitrification procedures, many kinds of attempts have been applied directly or indirectly to the oocyte and embryo in many species (Hwang et al., 2013; Chasombat et al., 2015; Hwang et al., 2016). In the present study, it was focused on the physical damages of the oocytes during vitrification procedures. It is well known that the vitrification procedures could affect cytoskeletal damage such microtubule dysfunction, spindle disorder, and mitochondrial function (Hara et al., 2012; 
Almasi Turk \& Roozbehi, 2013; Amoushahi et al., 2017). In the present study, we also tried to determine the appropriate timing for CB treatment either before or after vitrification procedure. Based on our results, the optimal timing of $\mathrm{CB}$ treatment was immediately after warming during recovery culture. The $\mathrm{CB}$ treatment before vitrification showed adverse effect on the survival rates of the postwarming oocytes similar with previous study (Marco-Jimenez et al., 2012). We concluded that this phenomenon might be related to shrinkage during vitrification procedure. The oocytes vitrified by $\mathrm{CB}$ might be shrunk easier than untreated oocyte because of its softened cytoskeletal followed by more difficult to swell up during warming.

In conclusion, the application of subdividing method is a very delicated method to determine the viability of postwarming pig oocyte. Also, the increased survival rates of post-warming pig oocyte treated with Vitri-CB method are firstly described here. The main finding is that short-term (30 min) treatment of the $\mathrm{CB}$ during recovery culture could be helpful to refresh the post-warming pig oocyte resulting improved survival rates.

\section{ACKNOWLEDGEMENTS}

This work was carried out with the support of "Animal Science \& Technology Development (Project No. PJ01335 401)" from Rural Development Administration, Korea.

\section{REFERENCES}

Albarracin JL, Morato R, Rojas C, Mogas T (2005) Effects of vitrification in open pulled straws on the cytology of in vitro matured prepubertal and adult bovine oocytes. Theriogenology 63:890-901.

Almasi Turk S, Roozbehi A (2013) Mouse oocytes and embryos cryotop-vitrification using low concentrated solutions: Effects on meiotic spindle, genetic material array and developmental ability. Iran J Basic Med Sci
16:599-601.

Amoushahi M, Salehnia M, Mowla SJ (2017) Vitrification of mouse MII oocyte decreases the mitochondrial DNA copy number, TFAM gene expression and mitochondrial enzyme activity. J Reprod Infertil 18:343-351.

Balaban B, Barut T, Urman B (2012) Assessment of oocyte quality. In: Nagy ZP, Varghese AC, Agarwal A (eds.), Practical Manual of In Vitro Fertilization: Advanced Methods and Novel Devices, Springer, New York.

Balaban B, Urman B, Sertac A, Alatas C, Aksoy S, Mercan R (1998) Oocyte morphology does not affect fertilization rate, embryo quality and implantation rate after intracytoplasmic sperm injection. Hum Reprod 13: 3431-3433.

Boyer P, Tourame P, Gervoise-Boyer M (2012) Oocyte vitrification and its impact on the clinical practice of assisted reproduction. Gynecol Obstet Fertil 40:687690

Chasombat J, Nagai T, Parnpai R, Vongpralub T (2015) Pretreatment of in vitro matured bovine oocytes with docetaxel before vitrification: Effects on cytoskeleton integrity and developmental ability after warming. Cryobiology 71:216-223.

Coticchio G, Bromfield JJ, Sciajno R, Gambardella A, Scaravelli G, Borini A, Albertini DF (2009) Vitrification may increase the rate of chromosome misalignment in the metaphase II spindle of human mature oocytes. Reprod Biomed Online 3:29-34.

Dai J, Wu C, Muneri CW, Niu Y, Zhang S, Rui R, Zhang D (2015) Changes in mitochondrial function in porcine vitrified MII-stage oocytes and their impacts on apoptosis and developmental ability. Cryobiology 41:291298.

De Sutter P, Dozortsev D, Qian C, Dhont M (1996) Oocyte morphology does not correlate with fertilization rate and embryo quality after intracytoplasmic sperm injection. Hum Reprod 11:595-597.

dela Pena EC, Takahashi Y, Atabay EC, Katagiri S, 
Nagano M (2001) Vitrification of mouse oocytes in ethylene glycol-raffinose solution: Effects of preexposure to ethylene glycol or raffinose on oocyte viability. Cryobiology 42:103-111.

Didion BA, Pomp D, Martin MJ, Homanics GE, Markert CL (1990) Observations on the cooling and cryopreservation of pig oocytes at the germinal vesicle stage. J Anim Sci 68:2803-2810.

Fabbri R, Porcu E, Marsella T, Primavera MR, Seracchioli R, Ciotti PM, Magrini O, Venturoli S, Flamigni C (1998) Oocyte cryopreservation. Hum Reprod 13:98-108.

Fuku E, Xia L, Downey BR (1995) Ultrastructural changes in bovine oocytes cryopreserved by vitrification. Cryobiology 32:139-156.

Hamamah S (2005) Oocyte and embryo quality: Is their morphology a good criterion? J Gynecol Obstet Biol Reprod (Paris) 34:5S38-5S41.

Hara H, Hwang IS, Kagawa N, Kuwayama M, Hirabayashi M, Hochi S (2012) High incidence of multiple aster formation in vitrified-warmed bovine oocytes after in vitro fertilization. Theriogenology 77:908-915.

Hwang IS, Hara H, Chung HJ, Hirabayashi M, Hochi S (2013) Rescue of vitrified-warmed bovine oocytes with rho-associated coiled-coil kinase inhibitor. Biol Reprod 89:1-6.

Hwang IS, Hochi S (2014) Recent progress in cryopreservation of bovine oocytes. Biomed Res Int 2014:570647.

Hwang IS, Kwon DJ, Kwak TU, Lee JW, Im GS, Hwang S (2016) Improved survival and developmental rates in vitrified-warmed pig oocytes after recovery culture with coenzyme Q10. Cryo Letters 37:59-67.

Hwang IS, Kwon DJ, Oh KB, Ock SA, Chung HJ, Cho IC, Lee JW, Im GS, Hwang S (2015) Production of cloned Korean native pig by somatic cell nuclear transfer. Dev Reprod 19:79-84.

Isachenko V, Soler C, Isachenko E, Perez-Sanchez F, Grishchenko V (1998) Vitrification of immature porcine oocytes: Effects of lipid droplets, temperature, cytoskeleton, and addition and removal of cryoprotectant. Cryobiology 36:250-253.

Kikuchi K, Ekwall H, Tienthai P, Kawai Y, Noguchi J, Kaneko H, Rodriguez-Martinez H (2002) Morphological features of lipid droplet transition during porcine oocyte fertilisation and early embryonic development to blastocyst in vivo and in vitro. Zygote 10:355-366.

Kono T, Kwon OY, Nakahara T (1991) Development of vitrified mouse oocytes after in vitro fertilization. Cryobiology 28:50-54.

Lowther KM, Weitzman VN, Maier D, Mehlmann LM (2009) Maturation, fertilization, and the structure and function of the endoplasmic reticulum in cryopreserved mouse oocytes. Biol Reprod 81:147-154.

Marco-Jimenez F, Casares-Crespo L, Vincente JS (2012) Effect if cytochalasin B pre-treatment of in vitro matured porcine oocytes before vitrification. Cryo Letters 33:24-30.

Mohr LR, Trounson AO (1980) The use of fluorescein diacetate to assess embryo viability in the mouse. J Reprod Fertil 58:189-196.

Mullen SF, Fahy GM (2012) A chronologic review of mature oocyte vitrification research in cattle, pigs, and sheep. Theriogenology 78:1709-1719.

Noto V, Campo R, Roziers P, Gordts S (1991) Fluorescein diacetate assessment of embryo viability after ultrarapid freezing of human multipronucleate embryos. Fertil Steril 55:1171-1175.

Pitchayapipatkul J, Somfai T, Matoba S, Parnpai R, Nagai T, Geshi M, Vongpralub T (2017) Microtubule stabilisers docetaxel and paclitaxel reduce spindle damage and maintain the developmental competence of in vitro-mature bovine oocytes during vitrification. Reprod Fertil Dev 29:2028-2039.

Rojas C, Palomo MJ, Albarracin JL, Mogas T (2004) Vitrification of immature and in vitro matured pig oocytes: Study of distribution of chromosomes, microtubules, and actin microfilaments. Cryobiology 49:211- 
220.

Somfai T, Kikuchi K, Nagai T (2012) Factors affecting cryopreservation of porcine oocytes. J Reprod Dev 58:17-24.

Vallorani C, Spinaci M, Bucci D, Porcu E, Tamanini C, Galeati G (2012) Pig oocyte vitrification by Cryotop method and the activation of the apoptotic cascade. Anim Reprod Sci 135:68-74.
Van Soom A, Mateusen B, Leroy J, de Kruif A (2003) Assessment of mammalian embryo quality: What can we learn from embryo morphology? Reprod Biomed Online 7:664-670.

Wang Q, Sun Q-Y (2006) Evaluation of oocyte quality: Morphological, cellular and molecular predictors. Reprod Fertil Dev 19:1-12. 